\title{
Text-Based Detection of the Risk of Depression
}

\author{
Jana M. Havigerová1*, Jiři Haviger2*, Dalibor Kučera ${ }^{3}$ and Petra Hoffmannová1 \\ 1 Institute of Psychology, Masaryk University, Brno, Czechia, ${ }^{2}$ Department of Informatics and Quantitative Methods, \\ University of Hradec Králové, Hradec Králové, Czechia, ${ }^{3}$ Department of Pedagogy and Psychology, University of South \\ Bohemia, České Budějovice, Czechia
}

OPEN ACCESS

Edited by:

Eva Kehayia

McGill University, Canada

Reviewed by:

Roel M. Willems,

Radboud University, Netherlands

Jovana Bjekić,

University of Belgrade, Serbia

*Correspondence: Jana M. Havigerová jamary@mail.muni.cz Jiř́ Haviger

jiri.haviger@uhk.cz

Specialty section:

This article was submitted to

Language Sciences,

a section of the journal

Frontiers in Psychology

Received: 15 April 2018

Accepted: 21 February 2019

Published: 18 March 2019

Citation:

Havigerová JM, Haviger J, Kučera D and Hoffmannová P (2019) Text-Based Detection of the Risk of Depression.

Front. Psychol. 10:513. doi: 10.3389/fpsyg.2019.00513
This study examines the relationship between language use and psychological characteristics of the communicator. The aim of the study was to find models predicting the depressivity of the writer based on the computational linguistic markers of his/her written text. Respondents' linguistic fingerprints were traced in four texts of different genres. Depressivity was measured using the Depression, Anxiety and Stress Scale (DASS-21). The research sample ( $N=172,83$ men, 89 women) was created by quota sampling an adult Czech population. Morphological variables of the texts showing differences (M-W test) between the non-depressive and depressive groups were incorporated into predictive models. Results: Across all participants, the data best fit predictive models of depressivity using morphological characteristics from the informal text "letter from holidays" (Nagelkerke $r^{2}=0.526$ for men and 0.670 for women). For men, models for the formal texts "cover letter" and "complaint" showed moderate fit with the data $\left(r^{2}=0.479\right.$ and 0.435$)$. The constructed models show weak to substantial recall $(0.235-0.800)$ and moderate to substantial precision (0.571 - 0.889). Morphological variables appearing in the final models vary. There are no key morphological characteristics suitable for all models or for all genres. The resulting models' properties demonstrate that they should be suitable for screening individuals at risk of depression and the most suitable genre is informal text ("letter from holidays").

Keywords: depression, genre, morphology, quantitative linguistics, predictive model

\section{INTRODUCTION}

\section{Depression}

The 10th Revision of International Classification of Diseases ICD-10, which is the basis for diagnosing mental disorders in the Czech Republic, classifies depression as an affective disorder (mood disorder). The disorder can have three forms: mild, moderate and severe forms of depression. One of the first symptoms is a change in mood toward the negative pole: the individual feels sad, needless, and/or unimportant. The disorder significantly affects self-confidence, which is often reflected in social relationships. It is typically accompanied by vegetative symptoms which can manifest as gastrointestinal problems (nausea, diarrhea etc.), tremors, sweating, or dry mouth. Sleep is also affected: the individual may have problems falling asleep, waking up, or staying asleep through the night. The effects of depression extend beyond the individual patient, with negative impact on patients' employers, spouses, and children (Scott, 1995; Stewart et al., 2003; Sills et al., 2007). 
According to the World Health Organization, depression is the most common mental disorder. Currently, 300 million people suffer from depression (WHO, 2017). The prevalence of depression in the adult population (i.e., clinical depression and definite depression) has been reported at approximately 5\% across cultures (Molarius and Janson, 2002; Probst et al., 2006; Munce and Stewart, 2007; Romans et al., 2007; Karger, 2014; Klimusová et al., 2016), and approximately 20\% in its milder form (partial symptoms, mild depression, and probable depression; Cho et al., 1998; Romans et al., 2007). The same studies also show that depression is almost twice as prevalent among women compared to men (some studies do not confirm these differences, e.g., Angst et al., 2002). The adult group most at risk is the middle-aged population (Murphy et al., 2000; Stordal et al., 2003; Klimusová et al., 2016). Some studies have reported slight differences in prevalence depending on race (e.g., the white population tended to have higher lifetime prevalence than the black population, Somervell et al., 1989) or according to residence (e.g., the prevalence of depression was significantly higher among rural than urban populations at 6.1 versus 5.2\%; Probst et al., 2006).

Worldwide, the prevalence of depression in the population is growing, with an increase of $18 \%$ between 2005 and 2015 (WHO, 2017). At the same time, early professional intervention results in improvement of psychological symptoms (e.g., lack of self-confidence, rumination, and anticipation of failure) and to elimination of somatic problems (e.g., gastrointestinal problems and sleeping disorders) in $80 \%$ of cases (Siu, 2016). Apart from the relief for the individual suffering from depression, intervention and treatment can significantly improve personal and public health as early detection leads to higher chances of returning to personal, social, and economic life (Reavley et al., 2013).

\section{Goals}

Early detection of an individual at risk of depression in initial stages and in mild form is beneficial both for the individual and society. Our study contributes to screening of individuals at risk of this disease. The study provides the original way of depression screening based on an analysis of how the writer uses the language to enable the automatic detection of writer's risk of depression.

\section{Related Works}

A frequent type of study focusing on the relationship between text variables and mood disorders (e.g., depression) is a case-study. Case studies analyze texts written spontaneously by authors (individuals) suffering from depression. An important example of this approach is Demjén's (2014) analysis of diaries and works of the American writer Sylvia Plath, who was suffering from lifetime depression and committed suicide in 1963 at the age of 30. In her study, Demjén focused on an analysis of metaphors used by people suffering from depression (i.e., metaphors of separation or loss of control). She found that Sylvia Plath used the second person singular when writing about experiences of conflict or separation. A quantitative analysis of whole texts (not only of the area of metaphors) showed that writers suffering from depression tended to use negative words and expressions with quantifiers with extreme poles (e.g., "everything," "nothing," "always," "never"; Demjén, 2014). Similar results were found in an analysis of texts of the traveler and surveyor Henry Hellyer, who committed suicide at the age of 42 . This analysis showed that the pronoun used most frequently was in the first person singular, while the use of the first person plural was much scarcer. Hellyer also tended to use negative words more often, like Sylvia Plath (Baddeley et al., 2011). Pennebaker and Chung (2007) analyzed spontaneous texts of two prominent representatives of Al-Qaeda (Zawahiri and Bin Laden), showing a surprising shift in the use of pronouns closely related to social status, individual and group identity, insecurity, and depression changes.

Automatisation of the processing of linguistic data has recently enabled the use of extensive research strategies. For example, Rude et al. (2004) asked 124 female students attending psychology seminars to write an essay about their deepest thoughts and feelings about college. The students also completed the Beck Depression Inventory, according to which they were divided into groups of currently depressed, formerly depressed and never-depressed people. The authors discovered a positive correlation between degrees of depression and use of the word "I" (i.e., pronouns in the first person singular) and a significantly scarcer use of the pronoun in the second and third persons. It is interesting that other pronouns in the first person singular ("me," "my" and "mine") do not show this correlation. Study based on LIWC analyzes conducted by Lieberman and Goldstein (2006) found that women with breast cancer who used more anger words improved in their health and quality of life, whereas women who used more anxiety words experienced increased depression. Ramírez-Esparza et al. (2008) compared the linguistic markers used by people who write about their depression in internet depression forums with linguistic markers used by people with breast cancer on bbc forums in English and in Spanish. It was found that online depressed writers used significantly more 1st person singular pronouns, less first person plural pronouns in both the English and Spanish forums. Women from depressed forums used less positive emotion words and more negative emotion words than women from breast cancer forums in English and Spanish. Sonnenschein et al. (2018) in their LIWC study provide evidence that the texts of people with mood disorders contain increasingly first-person singular pronouns, depressed as well as anxious, but differ in semantic terms (depressed patients used more words related to sadness). Van der Zanden et al. (2014) found that depression improvement during web-based psychological treatments based on textual communication was predicted by increasing use of 'discrepancy words' during treatment (e.g., would, should - a conditional in Czech language). Self-referencing verbal behavior appears to have specific interpersonal implications beyond general interpersonal distress and depressive symptoms (Zimmerman et al., 2013). A meta-analysis $(k=21, N=3758)$ of correlations between first person singular pronoun use and individual differences in depression (which occurs in a number of studies dealing with our topic) were conducted by Edwards and Holtzman (2017) who proven evidence that depression is linked to the use of first person singular pronouns $(r=0.13)$, this effect 
is not moderated by demographic factors, such as gender and there is little to no evidence of publication bias in this literature.

Several studies (e.g., Mairesse et al., 2007; Litvinova et al., 2016b) show that indexes combining several studied markers are also important. For example, a reliable predictor of self-destructive behavior (depression is one of the characteristics of such behavior) is the pronominalisation index: the ratio of pronouns to nouns (Litvinova et al., 2016b).

Existing studies do not only show relationships between the way of writing a text and mood disorders (e.g., depression and associated symptoms), but also a reciprocal healing effect of writing certain types of texts. For example, Sayer et al. (2015) conducted an experiment to test the effects of different writing styles using a sample of 1,292 Afghanistan and Iraq war veterans with self-reported reintegration difficulty. In their experiment, veterans who were instructed to write expressively experienced greater reductions in physical complaints, anger, and distress compared to veterans who were instructed to write factually, and, moreover, both writing groups showed reductions in PTSD symptoms and reintegration difficulty compared to veterans who did not write at all. The correlation between occurrence of words and successful intervention was also documented by Alvarez-Conrad et al. (2001).

Studies in clinical psychology clearly show that research on the relationship between the user of a language (e.g., speaker or writer) and their text is meaningful and has potential for the future. A worldwide and rapidly developing approach is the detection of the personality of authors from their texts, involving the design of predictive models based on correlations between quantifiable text parameters and individual psychological traits (Mairesse et al., 2007; Litvinova et al., 2016b). The present study was designed to add to this body of research.

\section{THE AIM OF THE PRESENT RESEARCH}

The study presented here focuses on discovery of the relationship between linguistic characteristics of a written text and the level of the emotional state of depression (depressivity) of its author. The focus is on non-content (non-semantic) computational linguistic markers of a written text. The main objective of the study is to find out which texts (and whether or not) can predict depression and what linguistic characteristics are involved in the eventual model. The key step is to create and evaluate predictive models to detect individuals at risk of depression from written texts. Into the models it is necessary to insert only a limited number of variables (DeVaus, 2002), therefore we carried out a two-stage reduction of input linguistic characteristics: (1) the variables having a low variability will be excluded, (2) the variables that can not distinguish between the depressive and non-depressive respondents will be excluded.

Gender differences: Due to the fact that there are gender differences in depression (Murphy et al., 2000; Stordal et al., 2003; Herring and Paolillo, 2006; Johannsen et al., 2015; Klimusová et al., 2016; Rafi, 2019) as well as gender differences in text processing (Litvinova et al., 2017) our analyses are conducted separately for men and women. We expect the results in each of the samples to differ in some features based on the gender of the writer.

Genre differences: Quantitative linguistic markers of a text are affected by the genre (Douglas, 1992; Stamatatos et al., 2000; Herring and Paolillo, 2006). Thus, the analyses are conducted on texts of four different genres. The genres are divided into two categories: formal (cover letter TXT1 and complaint TXT3) and informal texts (letter from holidays TXT2 and letter of apology TXT4).

Necessity and innovativeness of conducting the present study in Czech: Most research on the relationship between the linguistic properties of a text and its author's personal traits have been conducted with texts in English (e.g., Pennebaker's studies above). There is also research on texts in Chinese, Arabic, Spanish, Dutch, French, German, Italian, Russian, Turkish, and Serbian (e.g., Bjekić et al., 2014; Sikos et al., 2014; Sboev et al., 2016). According to Parkvall (2007), Czech is spoken by relatively few native speakers. With 10 million native speakers, Czech is the 83rd most used language in the world and the 15 th most frequently used language on the internet. In the studied context, Czech is an under-researched language (W3Techs, 2017) and, with the exception of our own preliminary research, we are aware of no other published research on the relationship between linguistic markers of a text and its writer's personality in Czech.

\section{MATERIALS AND METHODS}

\section{Measures \\ Depression, Anxiety and Stress Scale - 21 Items (DASS-21)}

The DASS-21 is a set of three self-report scales designed to measure the emotional states of depression, anxiety and stress. Each of the three subscales contains seven items. Each item is scored on a 4-point scale $(0=$ did not apply to me at all; 3 = applied to me very much or most of the time). Thus, a respondent can get 0 to 21 points for each subscale. The DASS-21 is based on a dimensional rather than a categorical conception of psychological disorders. The assumption on which the scale was developed (and which was confirmed by the research data) is that the differences between depression, anxiety and stress experienced by normal subjects and clinical populations are essentially differences of degree (Lovibond and Lovibond, 1995). In this study, we work with the subscale of depression, which assesses dysphoria, hopelessness, devaluation of life, selfdeprecation, and lack of interest/involvement, anhedonia, and inertia. In our study, we work with either the total score (0-21 points achieved) or with the cut-off score (non-depressive $\leq 6$, depressive $>6$ ), see Lovibond and Lovibond (1995).

Four fictive letters were written on a computer in a pre-defined electronic interface. All four letters were written by each participant. The recommended length of texts was 180-200 words. The participants could see the number of words used on the monitor. However, length was recommended, not strictly prescribed. The content of the text could be entirely fictional. 
The sequence of the four scenarios was selected randomly and each scenario was described to participants as follows:

Cover letter (TXT1, formal, positive sentiment): "You have found a job offer that captivated your interest and you aspire to be hired for this position. Therefore, you are going to write a letter to the company's director as a response to his/her offer trying to persuade the director that you are the right candidate for this position."

Letter from holidays (TXT2, informal, positive sentiment): "You are enjoying your time on an amazing vacation. Everything is going well, as expected, and you fully indulge in your popular activities. Therefore, you have decided to write a letter to your friend and convince him/her to come over and enjoy this perfect time with you."

Complaint (TXT3, formal, negative sentiment): "Until recently, you were satisfied with living in your apartment (or your house), not missing anything. Nevertheless, recent issues have made a hell out of a pleasant living. Although you originally strived to sort out the issues in a polite way, it did not help. Therefore, you decided to write an official complaint to the appropriate authorities."

Letter of apology (TXT4, informal, negative sentiment): "You have done something that substantially harmed your relationship with a person you were very close to for a long time. You had promised something that you did not fulfill. You feel sorry and you know that you made a mistake. Because you do not want to lose your close friend, you have decided to write a letter of apology to him/her."

The analyses were conducted on 688 texts that create a corpus of 99,481 words. In all texts, quantitative linguistic variables on various levels of classification (e.g., number of all adjectives, number of superlative forms of adjectives, number of words in singular, etc.) were automatically detected in the process of lemmatization with morphological tagging (Jelínek and Petkevič, 2011).

Quantitative linguistic variables are included in the analyses in the form of relativized isolated features (ratios) and compound indicators (special metrics) as described in the following lists.

Ratios (input $=16$ items):

- words per sentence: the number of words divided by the number of sentences,

- lemmas per sqrt words: the number of different lemmas (basic forms) divided by the square root of the number of words,

- sentence complexity: the number of finite verbs divided by the number of sentences,

- punctuations per sentence: the number of punctuation marks divided by the number of sentences,

- exclamation per sentence: the number of exclamation marks divided by the number of sentences,

- AN per ANNA: the number of adjective-noun pairs divided by the number of all pairs (adjective-noun plus noun-adjective),
- colloquial words per sentence: the number of colloquial words divided by the number of sentences,

- singularity index: the number of words in singular divided by the number of all words which have the grammatical category of interest (i.e., divided by the number of singular plus the number of plural plus the number of dual nouns),

- singularity $\mathrm{P}$ index: the number of possessive singular words divided by the number of all possessive words,

- vocative index: the ratio of words in vocative to the sum of all other words that have the grammatical category of interest,

- negativity index: the ratio of negative sentences to negative plus affirmative sentences,

- passive index: the number of words in passive divided by the number of words in passive and active,

- imperfectum index: the ratio of perfectum to perfectum plus imperfectum,

- dem per words: the number of diminutive words divided by the number of all words,

- vul per words: the number of vulgarisms divided by the number of all words,

- clq per words: the number of colloquial words divided by the number of all words.

Special metrics (input $=8$ items):

- coherence index: calculated using the formula Coh $=$ (particles + conjunctions + prepositions $) /(3 *$ sentence) (Litvinova et al., 2016b),

- pronominalisation index: the ratio of the total number of pronouns to the total number of nouns (Litvinova et al., 2016b),

- formality metric: is calculated using the formula $\mathrm{F}=$ (noun + adjective + preposition + article - pronoun - verb adverb - interjection + 100)/2 (Mairesse et al., 2007),

- trager index: number of verbs/number of adjectives (Sboev et al., 2016),

- readiness to action: number of verbs/number of nouns (Sboev et al., 2016),

- aggressiveness index: number of verbs/number of all words (Sboev et al., 2016),

- activity index: number of verbs / (number of verb + adjective + adverbs),

- autosemantic index: number of autosemantic words (noun, adjective, pronoun, numeral, verb, and adverb) in relation to number of words (Čech et al., 2014).

\section{Data Collection Procedure}

Participants were recruited using leaflets and advertisements on social networks. The participants were couples of people older than 15 who enrolled in the study voluntarily. After the study, they were awarded about 50 USD. Data collection was conducted in the controlled environment of a university on weekends from September 2016 to April 2017.

A battery of self-report psychological tests was administered with 4 fictive letters placed randomly between test blocks. The conditions of administration were always identical (the same 
environment, the same assistants) and relatively naturalistic to make the participants feel comfortable (they were allowed to relax when needed and an assistant was present). The maximum level of structure and identity of situation were strictly obeyed to eliminate the impact of structure of the situation on the correlation between linguistic markers of a text and its writer's personality (e.g., as discussed by Hirsh and Peterson, 2009).

\section{Participants}

Quota selection was used to sample participants. The decisive criterion for determination of quotas was age, gender, and education (Škrabal, 2014). The inclusion criteria were Czech citizenship, command of Czech as mother tongue, good psychical condition (without medication with psychopharmaceuticals), good knowledge of each other in each enrolled couple (that would allow the participants to describe each other sincerely and with a detached view). The participants declared fulfillment of conditions by signing a detailed informed agreement.

The sample is made of $N_{\text {resp }}=172$ respondents, out of whom $n_{\mathrm{m}}=83$ men, $n_{\mathrm{w}}=89$ women. The distribution with respect to age and education is given in Table 1 . The studied properties of the research sample correspond to distribution of the legally competent population in the Czech Republic, which makes generalization of results at this level possible.

\section{Data Analysis}

The analysis was conducted in seven steps. Outlier filtering: All texts showing outlying values for number of words $(<100)$ and number of sentences $(<5)$ were discarded. Reduction of variables, step one: low variability variables exclusion. Descriptive statistics for the studied QL variables were calculated and variables showing low level of variability were discarded from further calculations (if at least one of the following conditions were fulfilled: $\mathrm{mdn}=0$ or coefficient of variation $\mathrm{sd} / \mathrm{m}<0.05$ or $\mathrm{iqr} / \mathrm{mdn}<0.05)$. Assessment of normality: A Kolmogorov-Smirnov (K-S) test was conducted. Lowering granularity of depressive scale: The depression subscale of the DASS-21 ( $\min -\max =0-21$ ) was transformed to DASS21_01 (non-depressive $\leq 6$, depressive $>6$ ), see Lovibond and Lovibond (1995).

Reduction of variables, step two: exclusion variables with non-significant intergroup differences (depressive vs. non-depressive). This comparison was done using the Mann-Whitney test. It was conducted the 8 tests for four genres and two genders. Variables that didn't show significant differences in any of the 8 tests were excluded. Creation of models. Eight models were created using logistic regression (for four genres and two genders). Predictive models included only variables showing significant differences between the depressive and non-depressive group in the $\mathrm{M}-\mathrm{W}$ test (see step 5).

Evaluation of models: The criterion of the quality of each regression model was defined by the Nagelkerke coefficient $r^{2}>0.4$. To assess the predictive power of a model, the following coefficients were calculated: precision (the level of accuracy: the probability that a respondent marked by the model as depressive really is depressive) and recall (also known as sensitivity: the probability that a respondent who really is depressive is classified by the model as depressive). These coefficients are suitable for an unbalanced (unequal) sample (Chawla, 2005). The predictive power of the model was evaluated as sufficient if it met the following conditions: precision $>0.8$ and recall $>0.6$. The objectives of the study are exploratory and therefore it is not necessary to use multiple comparison correction (Li et al., 2016). The variables that were inserted into the models went through a two-step selection. Models were further verified according to predefined criteria (precision, recall).

TABLE 1 | Age group, education, and gender of participants $\left(N_{\text {resp }}=172\right)$.

\begin{tabular}{|c|c|c|c|c|c|c|}
\hline \multirow{2}{*}{ Gender } & & & \multicolumn{3}{|c|}{$\%$ of Total } & \multirow[b]{2}{*}{ Total \% } \\
\hline & & & \multicolumn{3}{|c|}{ Education } & \\
\hline \multirow[t]{3}{*}{ Male } & Age group & Younger than 25 & 7.2 & 7.2 & 1.2 & 15.7 \\
\hline & & $25-34$ & 1.2 & 14.5 & 6.0 & 21.7 \\
\hline & Total & & 14.5 & 63.9 & 21.7 & 100.0 \\
\hline \multirow[t]{4}{*}{ Female } & Age group & Younger than 25 & 5.6 & 5.6 & 1.1 & 12.4 \\
\hline & & 25 to 34 & 1.1 & 11.2 & 5.6 & 18.0 \\
\hline & & 35 to 55 & 2.2 & 24.7 & 6.7 & 33.7 \\
\hline & & Older than 55 & 2.2 & 27.0 & 6.7 & 36.0 \\
\hline \multirow{2}{*}{ Total } & & Older than 55 & 2.3 & 19.8 & 6.4 & 28.5 \\
\hline & Total & & 12.8 & 66.3 & 20.9 & 100.0 \\
\hline
\end{tabular}




\section{RESULTS}

\section{Verification of Assumptions and Preparation of Data for Testing and Creating Models \\ Outlier Filtering}

In each type of text, 1-4 outliers were detected (see Table 2), a total of 32 texts did not meet the conditions for entering analysis and were automatically discarded from further calculations. Thus, the analyses consisted of 656 texts.

\section{Reduction of Variables}

The stated conditions for variability were fulfilled by 13 quantitative linguistic variables out of the 24 followed ones. These 13 were included in further calculations.

\section{Assessment of Normality}

As expected, the studied variables were not normally distributed $(\mathrm{K}-\mathrm{S}$, sig $<0.05)$. Due to the non-normal distribution of data, only non-parametric/non-linear procedures were used in further calculations.

\section{Lowering Granularity of Depressive Scale}

The distribution of scores from the depression subscale of the DASS-21 was the following: men $\left(\mathrm{m}_{\mathrm{m}}=5.14, \mathrm{mdn}_{\mathrm{m}}=5\right.$, $\left.\min _{\mathrm{m}}=0, \max _{\mathrm{m}}=17\right)$, women $\left(\mathrm{m}_{\mathrm{w}}=4.04, \operatorname{mdn}_{\mathrm{w}}=3\right.$, $\left.\min _{\mathrm{w}}=0, \max _{\mathrm{W}}=16\right)$. Based on their results on the depression subscale, respondents were divided binarily into non-depressive and depressive groups (see Table 3). The cut-off point for these groups ( 6 points) was derived from the psychometric properties of the test (see Lovibond and Lovibond, 1995). The higher representation of men in the depressive category (about $1 / 3$ of men) compared to women (about 1/5 of women) reflects the characteristics of the research sample (it is unexpected and deserves a separate analysis; let us recall here that the respondents enrolled into the research voluntarily and were included by

TABLE 2 | Frequency of outliers $\left(N_{\text {resp }}=172, N_{\text {text }}=688\right)$.

\begin{tabular}{lccccc}
\hline & \multicolumn{2}{c}{ Male $\left(\boldsymbol{n}_{\mathbf{m}}=\mathbf{8 3}\right)$} & & \multicolumn{2}{c}{ Female $\left(\boldsymbol{n}_{\boldsymbol{f}}=\mathbf{8 9}\right)$} \\
\cline { 2 - 3 } \cline { 5 - 6 } \cline { 5 - 6 } & Non-outliers & Outliers & & Non-outliers & Outliers \\
\hline TXT1 & 81 & 2 & & 88 & 1 \\
TXT2 & 81 & 2 & & 85 & 4 \\
TXT3 & 81 & 2 & & 86 & 3 \\
TXT4 & 82 & 1 & & 88 & 1 \\
Total & 325 & 7 & & 347 & 9 \\
\hline
\end{tabular}

TABLE 3 | Frequency of depression in sample $\left(N_{\text {resp }}=172\right)$.

\begin{tabular}{lcc}
\hline DASS_D & Male $\left(\boldsymbol{n}_{\mathbf{m}}=\mathbf{8 3}\right)$ & Female $\left(\boldsymbol{n}_{\boldsymbol{f}}=\mathbf{8 9}\right)$ \\
\hline Non-depressive $(\mathrm{D} \leq 6)$ & $65.5 \%$ & $81.3 \%$ \\
Depressive $(\mathrm{D}>6)$ & $34.5 \%$ & $18.7 \%$ \\
Total & 100 & 100
\end{tabular}

quota selection. Thus, an identical distribution between men and women and higher prevalence in women were expected.).

\section{Testing of Intergroup Differences (Depressive vs. Non-depressive)}

The depressive and non-depressive groups were compared using a Mann-Whitney $U$ test $(\mathrm{M}-\mathrm{W}$ test, a non-parametric test for independent samples). The test was conducted separately for men and women as well as for each type of text. Table 4 shows an overview of significances of individual tests ( $U$ values and mean rank are available from the authors).

There was a significant difference in mean rank between the depressive and non-depressive groups for each of the selected linguistic variables (except for the coherence index) in at least one text. The only exception is the coherence index, which according to the result of $\mathrm{M}-\mathrm{W}$ test does not differentiate between depressive and non-depressive groups in any of the texts, and thus will be excluded from further calculations. Contrary to our expectations, a higher number of significant differences were found among men compared to women, and more often in formal texts (TXT1 and TXT3).

\section{Creating and Evaluating Models}

Eight regression models were created (for four texts among men and four texts among women). Table 5 presents an overview of significance for individual predictors for each model, with each column representing one model.

The quality of individual models is described in Table 6 (bold values indicate those model values that meet a predefined quality criterion and allow the model to be accepted).

The only model that fulfilled all the defined criteria is the model created on TXT2 (letter from holidays, informal text with positive sentiment) among women. The stated criteria are approximated by three models for men, namely models based on TXT1 (cover letter), 2 (letter from holiday) and 3 (letter of complaint).

\section{DISCUSSION}

The present study focuses on the relationships between linguistic properties of a written text and the level of its writer's currently experienced depressivity (based on the number of points achieved in the DASS-21 test, participants were divided into depressive and non-depressive group, and these two groups were compared). The chosen methodology is novel: (a) the source for analyses were texts written on an assigned topic under strictly controlled experimental conditions (i.e., not spontaneously written texts), (b) only formal, quantitative linguistic syntactical and morphological variables were subject to analyses (not semantic variables, i.e., only the verbal production, not its content were considered), (c) the research sample was representative of an adult population with respect to age and education (quota selection). We have not come across a study conducted using the same methodological basis. Methodologically similar studies are very scarce (e.g., Litvinova et al., 2016b tried to assess the 
TABLE 4 | Significance of intergroup differences in ql variables: Mann-Whitney $\left(N_{\text {resp }}=172, N_{\text {text }}=688\right)$.

\begin{tabular}{|c|c|c|c|c|c|c|c|c|}
\hline & \multicolumn{4}{|c|}{ Male $\left(n_{m}=83\right)$} & \multicolumn{4}{|c|}{ Female $\left(n_{f}=89\right)$} \\
\hline & TXT1 & TXT2 & TXT3 & TXT4 & TXT1 & TXT2 & TXT3 & TXT4 \\
\hline Singularity index & 0.213 & 0.175 & 0.503 & 0.374 & 0.120 & 0.653 & 0.008 & 0.459 \\
\hline Singularity_P index & 0.039 & 0.208 & 0.157 & 0.470 & 0.211 & 0.540 & 0.542 & 0.291 \\
\hline Negativity index & 0.026 & 0.000 & 0.013 & 0.122 & 0.664 & 0.613 & 0.863 & 0.399 \\
\hline Words per sentence & 0.125 & 0.266 & 0.062 & 0.020 & 0.676 & 0.475 & 0.916 & 0.750 \\
\hline Sentence complexity & 0.000 & 0.030 & 0.005 & 0.004 & 0.518 & 0.488 & 0.578 & 0.721 \\
\hline Punctuations per sentence & 0.130 & 0.826 & 0.458 & 0.612 & 0.290 & 0.420 & 0.487 & 0.009 \\
\hline Coherence index & 0.528 & 0.613 & 0.732 & 0.204 & 0.747 & 0.236 & 0.748 & 0.530 \\
\hline Pronom index & 0.059 & 0.279 & 0.006 & 0.205 & 0.131 & 0.711 & 0.210 & 0.469 \\
\hline Formality index & 0.023 & 0.086 & 0.001 & 0.062 & 0.112 & 0.566 & 0.523 & 0.317 \\
\hline Trager index & 0.022 & 0.011 & 0.011 & 0.032 & 0.128 & 0.117 & 0.846 & 0.189 \\
\hline Readiness_to_action index & 0.014 & 0.049 & 0.002 & 0.058 & 0.171 & 0.870 & 0.781 & 0.965 \\
\hline Aggressiveness index & 0.013 & 0.063 & 0.008 & 0.243 & 0.234 & 0.468 & 0.653 & 0.910 \\
\hline Activity index & 0.011 & 0.025 & 0.021 & 0.259 & 0.076 & 0.070 & 0.474 & 0.390 \\
\hline
\end{tabular}

TABLE 5 | Predictors of membership in depressive sample: Logistic regression.

\begin{tabular}{|c|c|c|c|c|c|c|c|c|}
\hline & \multicolumn{4}{|c|}{ Male $\left(\mathrm{n}_{m}=83\right)$} & \multicolumn{4}{|c|}{ Female $\left(n_{f}=89\right)$} \\
\hline & TXT1 & TXT2 & TXT3 & TXT4 & TXT1 & TXT2 & TXT3 & TXT4 \\
\hline Singularity index & 0.701 & 0.062 & 0.845 & 0.050 & 0.058 & 0.630 & 0.007 & 0.349 \\
\hline Singularity_P index & 0.044 & 0.630 & 0.017 & 0.585 & 0.112 & 0.392 & 0.746 & 0.728 \\
\hline Negativity index & 0.635 & 0.534 & 0.401 & 0.153 & 0.169 & 0.071 & 0.295 & 0.247 \\
\hline Words per sentence & 0.046 & 0.172 & 0.250 & 0.248 & 0.046 & 0.059 & 0.411 & 0.194 \\
\hline Sentence complexity & 0.004 & 0.089 & 0.575 & 0.536 & 0.198 & 0.050 & 0.618 & 0.201 \\
\hline Punctuations per sentence & 0.236 & 0.210 & 0.841 & 0.087 & 0.818 & 0.041 & 0.677 & 0.798 \\
\hline Pronom index & 0.661 & 0.042 & 0.017 & 0.720 & 0.385 & 0.682 & 0.740 & 0.323 \\
\hline Formality index & 0.479 & 0.631 & 0.025 & 0.723 & 0.525 & 0.605 & 0.234 & 0.236 \\
\hline Trager index & 0.639 & 0.759 & 0.019 & 0.841 & 0.599 & 0.139 & 0.186 & 0.182 \\
\hline Readiness_to_action index & 0.333 & 0.034 & 0.017 & 0.688 & 0.052 & 0.941 & 0.506 & 0.083 \\
\hline Aggressiveness index & 0.162 & 0.418 & 0.009 & 0.863 & 0.060 & 0.217 & 0.999 & 0.567 \\
\hline Activity index & 0.374 & 0.352 & 0.007 & 0.694 & 0.059 & 0.554 & 0.622 & 0.353 \\
\hline Constant & 0.431 & 0.170 & 0.059 & 0.637 & 0.639 & 0.248 & 0.086 & 0.914 \\
\hline
\end{tabular}

Each column represents a single model $\left(N_{\text {resp }}=172, N_{\text {text }}=688\right)$.

TABLE 6 | Coefficients of model quality and predictive power: Logistic regression $\left(N_{\text {resp }}=172, N_{\text {text }}=688\right)$.

\begin{tabular}{|c|c|c|c|c|c|c|c|c|}
\hline & \multicolumn{4}{|c|}{ Male $\left(n_{m}=83\right)$} & \multicolumn{4}{|c|}{ Female $\left(n_{f}=89\right)$} \\
\hline & TXT1 & TXT2 & TXT3 & TXT4 & TXT1 & TXT2 & TXT3 & TXT4 \\
\hline Nagelkerke $r^{2}$ & 0.479 & 0.526 & 0.435 & 0.310 & 0.330 & 0.670 & 0.324 & 0.284 \\
\hline Recall & 0.607 & 0.571 & 0.556 & 0.500 & 0.235 & 0.800 & 0.267 & 0.267 \\
\hline Precision & 0.739 & 0.889 & 0.789 & 0.647 & 0.571 & 0.889 & 0.667 & 0.667 \\
\hline
\end{tabular}

probability of self-destructive behavior of an individual via formal parameters of their texts).

One of the difficult questions was the choice of linguistic variables to include in the models. We have decided for a statistics-based procedure. In the first step, we have excluded variables with low variability. Sufficient variability has been proven for 6 of 16 selected single morpho-syntactic variables: the number of words per sentence, number of finite verbs per sentence, number of punctuation marks per sentence, proportional variables of relative occurrence of singular, possessive singular, negativity, and for all 8 indexes consisting of combinations and ratios of more morpho-syntactic characteristics: index of coherence, pronominalisation, formality, trager, readiness to action, aggressiveness and activity. This means that, in our study, only a limited amount of selected single morpho-synaptic characteristics was found to be suitable for use in distinguishing between non-depressive and non-depressive texts because of low variability; while all indexes showed sufficient 
variability. These results can support opinion that it is suitable to use indexes combining in formulas more morpho-syntactic characteristics of a text rather than focus attention on each of the observed linguistic characteristics as an insular unit when looking for relationships between a text and the characteristics of the writer of the text, as some other researchers stated (e.g., Litvinova et al., 2016b).

In step two it was verified discriminatory power of each from these 13 variables via $\mathrm{M}-\mathrm{W}$ test. The results confirmed that all proposed variables have sufficient discriminatory power to distinguish between texts (always at least one of the texts) of non-depressive and depressive people, except one. The exception is index of coherence. Contrary to our expectations, the present study does not validate the index of coherence (Litvinova et al., 2016b) as a suitable predictor of depression. This index is calculated as the sum of particles plus conjunctions plus prepositions divided by 3 times multiple of number of sentences. We believe that the reason why the index of coherence does not differentiate between non and depressive sample lies in the fact that the index includes the synsemantic parts of speech only. This explanation mirrors Pennebaker's (2011) argument that personality is most closely related to pronouns and other autosemantic words than synsemantic ones.

Thirteen linguistic variables (6 single morho-syntactic characteristics, 7 indexes combining more morphosyntactic characteristics) were included into the predictive models. Eight predictive models (for 4 different texts and 2 genders) were created and compared with each other. The results show that acceptable level of accuracy show models predicting depression in men sample from texts TXT1 (cover letter), TXT2 (letter from holidays) and TXT3 (complaint), and in women sample from TXT2 (letter from holidays). Across these 4 models, the probability that an individual will be detected as depressive when he/she is not (type II error) is lower than 0.2. The models for men sample show lower quality in criterion recall (their power to detect a depressive individual) than models for women sample. In other words, models built on texts written by men are more likely to fail to detect an individual with depression (type I error) than to erroneously classify an individual as depressive (type II error). Based on these results, it seems justified to state that, pursuant to the morpho-syntactic characteristics of the text, it is more confident to identify depressive women than depressive men.

For explanation, we need to look at gender differences in general and in our study as well. Most current studies show that women experience more depression than men do (e.g., Munce and Stewart, 2007; Klimusová et al., 2016) or the level of depression occurrence is the same for both men and women (Piccinelli and Wilkinson, 2000). However, in our study, men showed a higher level of currently experienced depression than women - it is opposite, unexpected trend. This might be a hit-or-miss feature of our research sample, the unexpected result of self-nomination sampling strategy. Previously diagnosed mental illness has been set as an exclusion criterion for self-nomination into our research no-clinical sample. Because men go to doctors with psychological problems less often than women (e.g., Angst et al., 2002 show that $48 \%$ of men and 59\% of women with depression seek a doctor), the women with the same intensive depressive symptoms have been visited their doctor and the previous diagnosis made them unable to enter the research as a non-clinical population. It is possible interpretation why there are more depressive men than women in our research sample, even though the prevalence of depression in men is generally lower. However, this circumstance does not explain why predictive model of women sample is stronger than men's sample predictive models.

The literature has repeatedly described that men and women generally differ in the preference of using some linguistic morpho-syntactic elements in their texts (e.g., Koppel et al., 2002; Argamon et al., 2003; Herring and Paolillo, 2006; Newman et al., 2008; Tausczik and Pennebaker, 2010; Rafi, 2019). Litvinova et al. (2016a) found some text parameters as reliable gender predictors: type-token ratio, formality index, a proportion of prepositions and pronoun-like adjectives, proportion of 100 most frequent words and ration of function (synsemnatic) words to content (autosemantic) words, some of them we operate too. Johannsen et al. (2015) presented a large-scale study of syntactic variation across 11 languages and found that there some universal gender-specific variations across languages: men seem to use numerals and nouns more than women, whereas women use pronouns and verbs more often, men use nominal compounds more often than women. From this point of view, the differences between models found in our study are understandable.

In our study, for women the model predicted depression from TXT2 (letter from holidays: informal text with positive situational sentiment) was of apparently higher quality then models predicting from other texts, while predictive models for men were of comparable quality (with respect to recall and precision metrics) across all the different texts. This result could be related to findings in other research. In this context Biber (1988) stated that women tend to express themselves in the form of "involved" writing while men prefer "informative" writing. Argamon et al. (2003) proved that women tend to present things in a relational way, while men in a non-fictional style of writing. Both cited facts may be related to the fact that the strongest predictive model was found in women just in the text, which is informal - closer to the natural way of verbal presentation of women.

Nor does this knowledge help explain differences found; it provides clear that models predicting the depression differ depending on gender, and that in the future it is necessary to take into account the moderative/mediatory influence of the writer/speaker's gender in modeling relationships between depression (or other personality characteristics) and text.

Overall, our results indicate that TXT4 (letter of apology) is not a suitable text for creation of a reliable and accurate model predicting depression. On the contrary, TXT2 (letter from holidays) seems to be suitable for creating a good fit predictive model for both men and women.

\section{Limitations}

The present study was conducted on a quota-selected sample of Czech native speakers. Generalization of the findings to Slavonic languages requires further research and generalization to non-Slavonic languages is not recommended. An unexpected 
limit of this study is the higher percentage of depressive men in the research sample. Due to the relatively small size of the research sample, we did not further verify the results (e.g., by using split half or cross validation).

\section{CONCLUSION}

The leading motivation for our research is to find ways to use automatic analysis of texts (such as cover letters, letters from holidays, blogs, and comments on social networks) to create predictive models that will reliably detect individuals at risk of a mental disorder (such as depression in the present study) so that they can be provided with help as early as possible. In the present study, we calculated four regression models to predict a higher emotional state of depression. The quality of our models indicates that depression can be predicted from informal text written about a holiday and that the quantitative linguistic characteristics that are most strongly suited to the proposed models for men are the pronominalisation index (the ratio of pronouns to nouns) and readiness to action index (the ratio of verbs to nouns) and for women are sentence complexity (the ratio of finite verbs to number of sentences) and punctuation (the ratio of number of punctuation to number of sentences). We plan to extend our future research to a clinical population to analyze the texts of people with a diagnosed mental disorder, especially with depression or phobias. Given our results and the results of other research (e.g., Rude et al., 2004) we plan to pay more attention to autosemantic words, especially to various types of pronouns.

\section{DATA AVAILABILITY}

The datasets generated and analyzed in this study are available on request from the authors of the article. If interested, please contact the corresponding author.

\section{REFERENCES}

Alvarez-Conrad, J., Zoellner, L. A., and Foa, E. B. (2001). Linguistic predictors of trauma pathology and physical health. Appl. Cogn. Psychol. 15, 159-170. doi: 10.1002/acp.839

Angst, J., Gamma, A., Gastpar, M., Lépine, J.-P., Mendlewicz, J., and Tylee, A. (2002). Gender differences in depression. Eur. Arch. Psychiatry Clin. Neurosci. 252, 201-209. doi: 10.1007/s00406-0020381-6

Argamon, S., Koppel, M., Fine, J., and Shimoni, A. R. (2003). Gender, genre, and writing style in formal written texts. Text 23, 321-346. doi: 10.1515/text.2003. 014

Baddeley, J. L., Daniel, G. R., and Pennebaker, J. W. (2011). How Henry Hellyer's use of language foretold his suicide. Crisis 32, 288-292. doi: 10.1027/0227-5910/ a000092

Biber, D. (1988). Variation Across Speech and Writing. Cambridge: Cambridge University Press.

Bjekić, J., Lazarević, L. B., Živanović, M., and Knežević, G. (2014). Psychometric evaluation of the Serbian dictionary for automatic text analysis-LIWCser. Psihologija 47, 5-32.

Čech, R., Popescu, I., and Altmann, G. (2014). Metody kvantitativní analýzy (nejen) básnických textù. Olomouc: Univerzita Palackého.

\section{ETHICS STATEMENT}

The project was approved by the Ethics committee of the University of South Bohemia (headed by professor Hana Šantrůčková, president of the Ethics committee of the USB) that confirmed the project was carried out in accordance with the recommendations of the Ethical code of the University of South Bohemia in České Budéjovice. All subjects gave written informed consent in accordance with the Declaration of Helsinki.

\section{AUTHOR CONTRIBUTIONS}

DK brought the original idea and was the main solver of the grant project. $\mathrm{JMH}$ and $\mathrm{JH}$ formulated the goals of the study and all authors studied and discussed the relationship between the text and its writer. DK arranged a complete collection of quota sample data. JMH arranged a complete collection of clinical sample data. DK, JH, and JMH designed the online collection, pre-processing, and retention of the data. JMH and $\mathrm{PH}$ wrote the introduction. $\mathrm{JH}$ designed the data processing procedure, performed all the mathematical and statistical calculations, and described the results. JMH thought out and wrote the discussion and all authors improved the content and formulations of the manuscript. JMH formatted the text and DK ensured professional proofreading and uploading of the manuscript for the review process.

\section{FUNDING}

The research Computational Psycholinguistic Analysis of Czech Text (CPACT) is funded by the Czech Science Foundation (GA ČR) grant no. 1619087S.

Chawla, N. V. (2005). "Data mining for imbalanced datasets: an overview," in Data Mining and Knowledge Discovery Handbook, eds O. Maimon and L. Rokach (Boston, MA: Springer), 853-867. doi: 10.1007/0-387-25465X_40

Cho, M. J., Nam, J. J., and Suh, G. H. (1998). Prevalence of symptoms of depression in a nationwide sample of Korean adults. Psychiatry Res. 81, 341-352. doi: 10.1016/s0165-1781(98)00 $122-\mathrm{x}$

Demjén, Z. (2014). Drowning in negativism, self-hate, doubt, madness: linguistic insights into Sylvia Plath's experience of depression. Commun. Med. 11, 41-54. doi: 10.1558/cam.v11i1.18478

DeVaus, D. (2002). Analyzing Social Science Data: 50 Key Problems in Data Analysis. Los angeles, CA: SAGE Publications.

Douglas, D. (1992). The multi-dimensional approach to linguistic analyses of genre variation: an overview of methodology and findings. Comput. Hum. 26, 331-345. doi: 10.1007/bf00136979

Edwards, M., and Holtzman, N. S. (2017). A meta-analysis of correlations between depression and first person singular pronoun use. J. Res. Pers. 68, 63-68. doi: 10.1016/j.jrp.2017.02.005

Herring, S. C., and Paolillo, J. C. (2006). Gender and genre variation in weblogs. J. Sociolinguistics 10, 439-459. doi: 10.1111/j.1467-9841.2006. 00287.x 
Hirsh, J. B., and Peterson, J. B. (2009). Personality and language use in selfnarratives. J. Res. Pers. 43, 524-527. doi: 10.1016/j.jrp.2009.01.006

Jelínek, T., and Petkevič, V. (2011). "Systém jazykového značkování současné psané češtiny," in Korpusová lingvistika: Gramatika a značkování korpusù, Vol. 3, ed. F. Čermák (Praha: Nakladatelství Lidové noviny), 154-170.

Johannsen, A., Hovy, D., and Søgaard, A. (2015). "Cross-lingual syntactic variation over age and gender," in Proceedings of the 19th Conference on Computational Language Learning, Beijing, 103-112.

Karger, A. (2014). Geschlechtsspezifische aspekte bei depressiven erkrankungen. Bundesgesundheitsblatt Gesundheitsforschung Gesundheitsschutz 57, 1092-1098. doi: 10.1007/s00103-014-2019-z

Klimusová, H., Burešová, I., Dosedlová, J., and Jelínek, M. (2016). “Association of optimism and health-related behavior with mental health in Czech adolescents," in The European Proceedings of Social \& Behavioural Sciences, eds Z. Bekirogullari, M. Y. Minas, and R. X. Thambusamy (Amsterdam: Future Academy), 598-605. doi: 10.15405/epsbs.2016.11.62

Koppel, M., Argamon, S., and Shimoni, A. (2002). Automatically categorizing written texts by author gender. Literary Linguist. Comput. 17, 401-412. doi: $10.1093 / 11 c / 17.4 .401$

Li, G., Taljaard, M., Van den Heuvel, E. R., Levinne, M. A. H., Cook, D. J., Wells, G. A., et al. (2016). An introduction to multiplicity issues in clinical trials: the what, why, when and how. Int. J. Epidemiol. 46, 746-755. doi: 10.1093/ije/ dyw320

Lieberman, M. A., and Goldstein, B. A. (2006). Not all negative emotions are equal: the role for emotional expression in online support groups for women with breast cancer. Psychooncology 15, 160-168. doi: 10.1002/ pon. 932

Litvinova, T., Seredin, P., Litvinova, O., and Zagorovskaya, O. (2017). “Differences in type-token ratio and part-of-speech frequencies in male and female Russian written texts," in Proceedings of the Workshop on Stylistic Variation, Copenhagen, 69-73. doi: 10.18653/v1/w17-4909

Litvinova, T., Seredin, P., Litvinova, O., Zagorovskaya, O., Sboev, A., Gudovskih, D., et al. (2016a). "Gender prediction for authors of Russian texts using regression and classification techniques," in Proceedings of the Third International Workshop on Concept Discovery in Unstructured Data (CDUD 2016), Moscow, 44-54.

Litvinova, T., Zagorovskaya, O., Litvinova, O., and Seredin, P. (2016b). Profiling a set of personality traits of a text's author: a corpus-based approach. Speech Comput. 9811, 555-562. doi: 10.1007/978-3-319-43958-7_67

Lovibond, S. H., and Lovibond, P. F. (1995). The structure of negative emotional states: comparison of the depression anxiety stress scales (DASS) with the beck depression and anxiety inventories. Behav. Res. Ther. 33, 335-343. doi: 10.1016/0005-7967(94)00075-u

Mairesse, F., Walker, M. A., Mehl, M. R., and Moore, R. K. (2007). Using linguistic cues for the automatic recognition of personality in conversation and text. J. Artif. Intell. Res. 30, 457-500.

Molarius, A., and Janson, S. (2002). Self-rated health, chronic diseases, and symptoms among middle-aged and elderly men and women. J. Clin. Epidemiol. 55, 364-370. doi: 10.1016/s0895-4356(01)00491-7

Munce, S. E., and Stewart, D. E. (2007). Gender differences in depression and chronic pain conditions in a national epidemiologic survey. Psychosomatics 48, 394-399. doi: 10.1176/appi.psy.48.5.394

Murphy, J. M., Laird, N. M., Monson, R. R., Sobol, A. M., and Leighton, A. H. (2000). Incidence of depression in the Stirling County study: historical and comparative perspectives. Psychol. Med. 30, 505-514. doi: 10.1017/ s0033291799002044

Newman, M. L., Groom, C. J., Handelman, L. D., and Pennebaker, J. W. (2008). Gender differences in language use: an analysis of 14,000 text samples. Discourse Process. 45, 211-236. doi: 10.1080/01638530802073712

Parkvall, M. (2007). Nationalencyklopedin. Available at: https://en.wikipedia.org/ wiki/Nationalencyklopedin

Pennebaker, J. W. (2011). The Secret Life of Pronouns: What Our Words Say About $U s$. New York, NY: Bloomsbury Press.

Pennebaker, J. W., and Chung, C. K. (2007). "Computerized text analysis of AlQaeda transcripts," in A Content Analysis Reader, eds K. Krippendorff and M. Bock (Thousand Oaks, CA: Sage), 2007.

Piccinelli, M., and Wilkinson, G. (2000). Gender differences in depression: critical review. Br. J. Psychiatry 177, 486-492. doi: 10.1192/bjp.177.6.486
Probst, J. C., Laditka, S. B., Moore, C. G., Harun, N., Powell, M. P., and Baxley, E. G. (2006). Rural-urban differences in depression prevalence: implications for family medicine. Fam. Med. 38, 653-660.

Rafi, M. S. (2019). SMS Text Analysis: Language, Gender and Current Practices. https://www.tesol-france.org/uploaded_files/files/Coll07-Shaban-Rafi.pdf

Ramírez-Esparza, N., Chung, C. K., Kacewicz, E., and Pennebaker, J. W. (2008). "The psychology of word use in depression forums in English and in Spanish: testing two text analytic approaches," in Proceedings of the Second International Conference on Weblogs and Social Media, ICWSM 2008, Seattle, WA.

Reavley, N. J., Morgan, A. J., and Jorm, A. F. (2013). Development of scales to assess mental health literacy relating to recognition of and interventions for depression, anxiety disorders and schizophrenia/psychosis. Aust. N. Z. J. Psychiatry 48, 61-69. doi: 10.1177/0004867413491157

Romans, S. E., Tyas, J., Cohen, M. M., and Silverstone, T. (2007). Gender differences in the symptoms of major depressive disorder. J. Nerv. Ment. Dis. 195, 905-911. doi: 10.1097/nmd.0b013e318159 $4 \mathrm{cb} 7$

Rude, S., Gortner, E., and Pennebaker, J. W. (2004). Language use of depressed and depression-vulnerable college students. Cogn. Emot. 18, 1121-1133. doi: 10.1080/02699930441000030

Sayer, N. A., Noorbaloochi, S., Frazier, P. A., Pennebaker, J. W., Orazem, R. J., Schnurr, P. P., et al. (2015). Randomized controlled trial of online expressive writing to address readjustment difficulties among U.S. Afghanistan and Iraq war veterans. J. Trauma. Stress 28, 381-390. doi: 10.1002/jts. 22047

Sboev, A., Litvinova, T., Gudovskikh, D., Rybka, R., and Moloshnikov, I. (2016). Machine learning models of text categorization by author gender using topicindependent features. Procedia Comput. Sci. 101, 135-142. doi: 10.1016/j.procs. 2016.11.017

Scott, J. (1995). Psychotherapy for bipolar disorder. Br. J. Psychiatry 167, 581-588. doi: 10.1192/bjp.167.5.581

Sikos, J., David, P., Habash, N., and Faraj, R. (2014). "Authorship analysis of inspire magazine through stylometric and psychological features," in Proceedings of the 2014 IEEE Joint Intelligence and Security Informatics Conference, Hague. doi: $10.1109 /$ jisic. 2014.15

Sills, M. R., Shetterly, S., Xu, S., Magid, D., and Kempe, A. (2007). Association between parental depression and children's health care use. Pediatrics 119, e829-e836.

Siu, A. L. (2016). Screening for depression in children and adolescents: US Preventive Services Task Force recommendation statement. JAMA 315, 380-387. doi: 10.1542/peds.2015-4467

Škrabal, J. (2014). Úroveň Vzdělání Obyvatelstva Podle Výsledkù Sčitání Lidu. Available at: https://www.czso.cz/documents/10180/20536250/17023214.pdf/ 7545a15a-8565-458b-b4e3-e8bf43255b12?version=1.1

Somervell, P. D., Leaf, P. J., Weissman, M. M., Blazer, D. G., and Bruce Livingston, M. L. (1989). The prevalence of major depression in Black and White adults in five United States communities. Am. J. Epidemiol. 130, 725-735. doi: 10.1093/ oxfordjournals.aje.a115394

Sonnenschein, A. R., Hofmann, S. G., Ziegelmayer, T., and Lutz, W. (2018). Linguistic analysis of patients with mood and anxiety disorders during cognitive behavioral therapy. Cogn. Behav. Ther. 47, 315-327. doi: 10.1080/16506073. 2017.1419505

Stamatatos, E., Fakotakis, N., and Kokkinakis, G. (2000). Automatic text categorization in terms of genre and author. Comput. Linguist. 26, 471-495. doi: 10.1162/089120100750105920

Stewart, W. F., Ricci, J. A., Chee, E., Hahn, S. R., and Morganstein, D. (2003). Cost of lost productive work time among US workers with depression. JAMA 289, 3135-3144.

Stordal, E., Mykletun, A., and Dahl, A. A. (2003). The association between age and depression in the general population: a multivariate examination. Acta Psychiatr. Scand. 107, 132-141. doi: 10.1034/j.1600-0447.2003. 02056.x

Tausczik, Y. R., and Pennebaker, J. W. (2010). The psychological meaning of words: LIWC and computerized text analysis methods. J. Lang. Soc. Psychol. 29, 24-54. doi: 10.1177/0261927x09351676

Van der Zanden, R., Curie, K., Van Londen, M., Kramer, J., Steen, G., and Cuijpers, P. (2014). Web-based depression treatment: associations of clients $\times$ 
word use with adherence and outcome. J. Affect. Disord. 160, 10-13. doi: 10. 1016/j.jad.2014.01.005

W3Techs (2017). Usage of Content Languages for Websites. Available at: https: //w3techs.com/technologies/overview/content_language/all

WHO (2017). Depression. Available at: http://www.who.int/mediacentre/ factsheets/fs369/en

Zimmerman, J., Wolf, M., Bock, A., Peham, D., and Benecke, C. (2013). The way we refer to ourselves reflects how we relate to others: associations between first-person pronoun use and interpersonal problems. J. Res. Pers. 47, 218-225. doi: 10.1016/j.jrp.2013. 01.008
Conflict of Interest Statement: The authors declare that the research was conducted in the absence of any commercial or financial relationships that could be construed as a potential conflict of interest.

Copyright (c) 2019 Havigerová, Haviger, Kučera and Hoffmannová. This is an openaccess article distributed under the terms of the Creative Commons Attribution License (CC BY). The use, distribution or reproduction in other forums is permitted, provided the original author(s) and the copyright owner(s) are credited and that the original publication in this journal is cited, in accordance with accepted academic practice. No use, distribution or reproduction is permitted which does not comply with these terms. 